\title{
Scientific Institutions Should Support Inclusive Engagement: Reflections on the AAAS Center for Public Engagement Approach
}

\author{
Elana Kimbrell, Gemima Philippe and Mary Catherine Longshore* \\ Center for Public Engagement with Science and Technology, American Association for the Advancement of Science, \\ Washington, DC, United States
}

Scientists' engagement with society on critical environmental and health issues is essential to reaching positive and equitable long-term outcomes. We argue that stronger institutional support for public engagement is necessary and that inclusive practices should be built into public engagement training and relationships. The American Association for the Advancement of Science (AAAS)'s Center for Public Engagement

OPEN ACCESS

Edited by:

Brianne Suldovsky, Portland State University,

United States

Reviewed by:

Hollie Smith,

University of Oregon, United States

Justin Reedy,

University of Oklahoma, United States

*Correspondence:

Mary Catherine Longshore

mlongshore@aaas.org

Specialty section:

This article was submitted to

Science and Environmental

Communication,

a section of the journal

Frontiers in Communication

Received: 30 September 2021

Accepted: 14 December 2021

Published: 10 January 2022

Citation:

Kimbrell E, Philippe G and Longshore MC (2022) Scientific Institutions Should Support Inclusive Engagement: Reflections on the AAAS

Center for Public

Engagement Approach.

Front. Commun. 6:787349.

doi: $10.3389 /$ fcomm.2021.787349 with Science and Technology provides a model of support for scientists that we believe other scientific institutions can replicate and expand on. This model prioritizes representative and accessible science communication training, resources (e.g., funding and staff and peer support), opportunities to practice engagement, and rewards and incentives for doing engagement. We describe our programs in each of these areas and reflect on how well each builds scientists' engagement skills and institutional capacity, and whether each embodies and models thoughtful, accessible, and representative engagement. Through these various approaches, the Center communicates to other scientific institutions that engagement by scientists should be valued, celebrated, and supported, and builds capacity for individual scientists to do effective engagement. We argue that these supports can be applied by other scientific institutions to reflect and incorporate society's diverse needs and concerns, thus truly serving the public and making science and scientific institutions stronger for it.

Keywords: science communication, public engagement, institutional change, inclusive engagement, health communication, climate communication, science communication training, engagement incentives

\section{INTRODUCTION}

Scientists' engagement with society on pivotal environmental and health issues is essential to reaching equitable outcomes. To be successful, scientists require support in the form of training, resources, and incentives. We argue for increased institutional support for public engagement and reflect on our holistic approach as a catalyst for discussions on doing this well, considering especially whether our programs are inclusive, accessible, and representative.

The Center for Public Engagement with Science and Technology ("the Center") at the American Association for the Advancement of Science (AAAS) was founded in 2004 with the vision of facilitating dialogue between science and society and providing scientists with training and opportunities to thoughtfully engage the public in two-way dialogue (Leshner, 2003). 
AAAS CENTER FOR PUBLIC ENGAGEMENT WITH SCIENCE AND TECHNOLOGY

Theory of Change
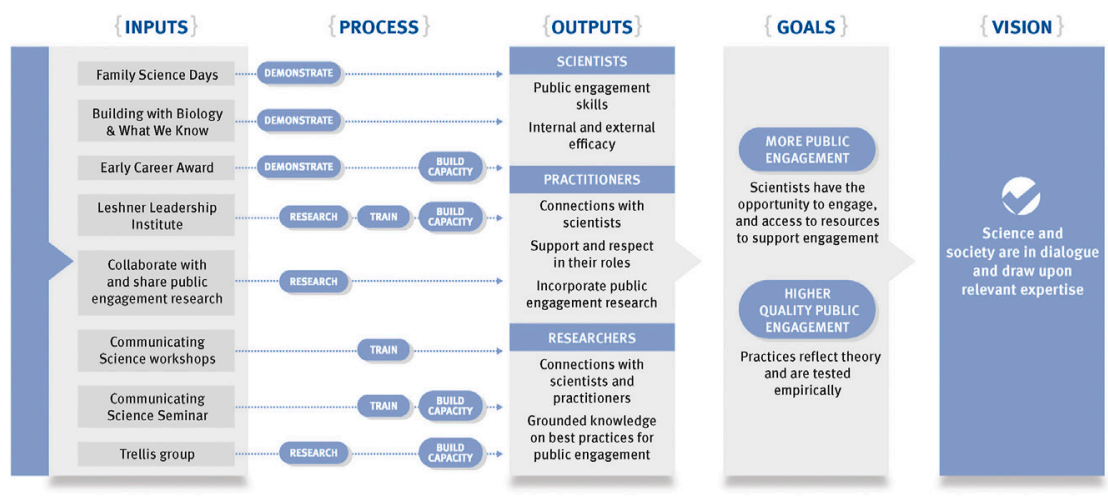

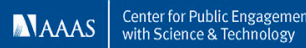

FIGURE 1 | Theory of change for the AAAS center for public engagement with science and technology (2015).

We encourage scientists ${ }^{1}$ to use the public engagement with science approach, defined as "intentional, meaningful interactions that provide opportunities for mutual learning between scientists and members of the public," (Braha, 2015, 18) hereinafter "public engagement." This practice incorporates, but is distinct from, the skills-centric discipline of science communication (MacArthur et al., 2020, 63), specifically encouraging scientists to learn from the public. Building on this definition, inclusive public engagement is intentional, reciprocal, and reflexive (Canfield and Menezes, 2020, 1-2), focusing on longer-term relationship-building with communities and on communities' self-defined needs and assets.

We recommend scientists incorporate inclusive public engagement into their scientific work and use it to improve both their research and public outcomes -- for which institutional support is critical. We argue that a holistic approach, beginning with 1) training, and incorporating 2) resources, 3) opportunities to practice engaging, and 4) rewards and incentives for doing public engagement, is essential. Here, we reflect on our Center's approach to institutional support by examining how some of our programs demonstrate these pillars of support. Our goals and approach stemmed in part from several meetings and workshops AAAS held in 2014 and 2015 to help us develop a theory of change for the Center (Figure 1), as well as a visual model (Figure 2) and theory of change for public engagement with science more

\footnotetext{
${ }^{1}$ We use the term "scientists" to refer to researchers and practitioners identifying with the scientific community, including but not limited to research scientists, applied scientists, engineers, and medical professionals.
}

broadly (AAAS Center for Public Engagement with Science and Technology, 2016).

\section{TRAINING}

Institutions providing science communication and public engagement training signal that public engagement is a priority and provide scientists with tools to succeed. Our primary training program is an example of this.

\section{Communicating Science Workshops Program}

The Center launched the AAAS Communicating Science Program $^{2}$ in 2008 and has trained more than 16,000 scientists. The program was created to fill an institutional gap: graduate degree programs in science do not often offer science communication curricula, despite evidence that effective communication and engagement skills are useful within science and more broadly (Aurbach et al., 2019; Bartel et al., 2019). Our goal for the program is to give scientists the tools they need to effectively engage in conversations within broader society, especially on critical societal issues informed by science.

AAAS trainings use our Public Engagement Framework, which provides structure for planning, implementing, and evaluating audience-centric, dialogue-based, inclusive public engagement, with the intent that this structure or manner of

${ }^{2}$ https://www.aaas.org/programs/communicating-science 
PUBLIC ENGAGEMENT WITH SCIENCE:

A Visual Model

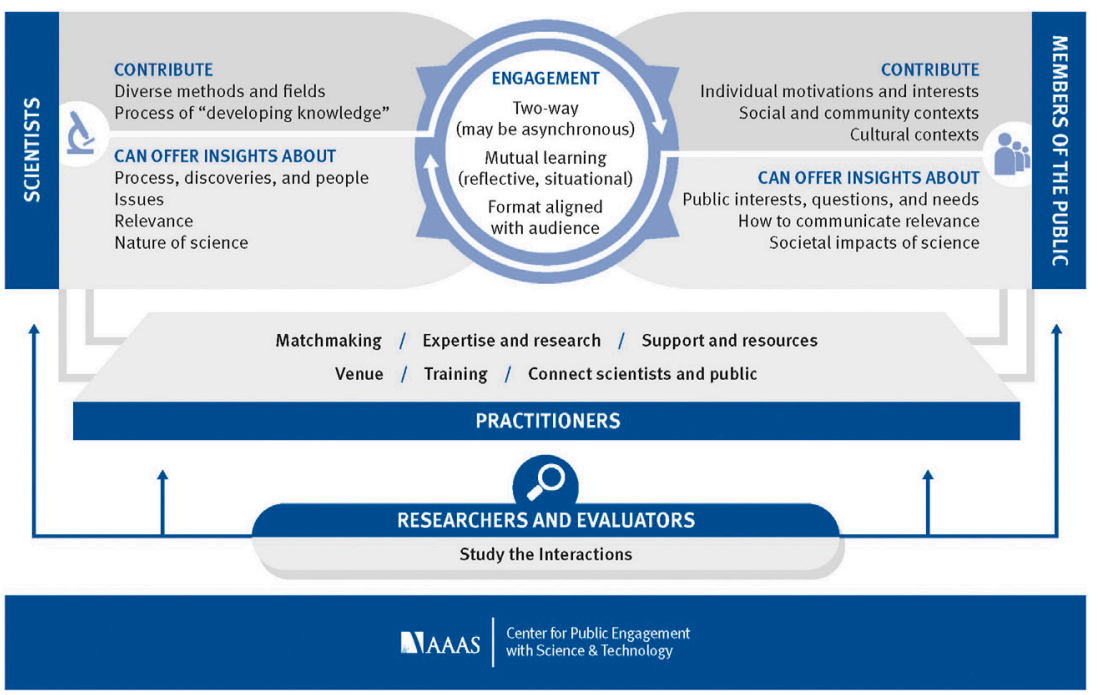

FIGURE 2 | Visual model for public engagement with science (2015).

thinking is integrated into both projects and careers (Risien and Storksdieck, 2018). This approach prioritizes thoughtful planning and responsiveness to audiences (including listening and being openminded-e.g., what can the scientist learn from the public?) while also providing guidance on how to be clear and succinct to capture attention and enable conversations. The training also introduces different methods of engagement, including 1) informal "public dialogue" with the goal of learning occurring both by experts and the public, 2) "policy deliberation" with the goals of exchanging views about science policy, 3) "knowledge coproduction" wherein scientists partner with members of the public to collaboratively do research, and 4) "University-led cooperative engagement" such as engagement done through university extension offices (Storksdieck et al., 2016).

To reinforce both the importance of approaching public engagement thoughtfully and strategically, and that support for this work exists, we encourage institutional leaders to make remarks during workshops and, when possible, point participants to resources at their institutions. Post-workshop survey results tell us that trainings establish some momentum for scientists wishing to engage or increase their engagement. In 2020, three-quarters of participants reported being more aware of and feeling more connected to colleagues doing public engagement, likely a result of small-group discussions with colleagues during workshops, and two-thirds reported new awareness of their institution's support for public engagement. Often, hosts ask us how to build on this momentum and we encourage them to highlight or create resources to support scientists who wish to engage, the pillar we explore next. Training, when provided in isolation, is not enough to enable scientists to effectively engage.

An additional critical component of this program is accessibility: ensuring everyone has access to quality training that meets their needs is one part of ensuring public engagement itself is inclusive and representative. AAAS models this in our trainings by employing accessible design (Murchiea and Diomede, 2020), informed by a style guide with one simple typeface and a colorblind-compliant color palette (Crameri et al., 2020), and making plain-text versions of presentations available. When facilitating training events or giving talks, staff use microphones and Microsoft PowerPoint closed captioning (Cooke et al., 2020).

We have seen this commitment to accessibility influence our customers. During planning calls with hosting institutions, we ask about participants' accommodation needs. Often, hosts have not thought about this. In 2021, one host shared that this question made them realize their program needed to think more about accessibility.

In 2020, the Center launched virtual training products, opening them to individuals, and to institutions with remote staff, for the first time. Although opening workshops to individuals has allowed us to reach more scientists, we acknowledge that our registration fees are a barrier to entry and are exploring developing additional resources to meet this need. The program continues to evolve with insight from pre- and post-workshop evaluations, longitudinal feedback, and facilitator experiences.

\section{RESOURCES}

Providing scientists with training and inspiring them to act is an important first step, but it must be combined with dedicated resources to enable action, including funding, staff support, and 
peer networks. These resources sustain public engagement efforts to drive societal change, inspire new generations of scientists, and fulfill institutions' missions. Here we examine two programs providing such resources.

\section{IF/THEN ${ }^{\circledR}$ Ambassador Program}

In 2019, the Center created the AAAS IF/THEN ${ }^{\circledR}$ Ambassador program in partnership with Lyda Hill Philanthropies' IF/THEN ${ }^{\circledast}$ Initiative ${ }^{3}$, which aims to close the representation gap for women in STEM, particularly as viewed through the media and pop culture. The program is designed to help middle school girls see themselves as the scientists of the future, engaging them at a critical time when science curricula become more challenging, and girls are not encouraged to pursue science in the same way boys are (Geena Davis Institute on Gender in Media, 2018).

Through the AAAS IF/THEN ${ }^{\circledR}$ Ambassadors project, the Center recruited and empowered a diverse cohort of 125 women in a range of STEM careers. Ambassadors received initial professional development via a 3-day summit. They also received a monetary award, the opportunity to apply for a $\$ 10,000$ "She Can Change the World Project" grant, an online network of ambassadors and support staff, weekly resource emails, and connections with IF/THEN ${ }^{\circledast}$ Coalition members including the Girl Scouts, Nepris (which connects industry professionals with classroom educators), and the Association of Science and Technology Centers (ASTC). Continuing professional development and one-on-one coaching from AAAS staff help assist ambassadors in becoming high-profile role models in the media and in developing learning materials, engaging directly with middle-school girls, and writing grants for public engagement project funding.

The IF/THEN ${ }^{\circledR}$ "She Can Change the World Projects" have allowed ambassadors to apply their training and invest in engagement projects with audiences they care about. For example, Tiffany Panko, a deaf physician, created a women's health book, $H$ is for Hormones ${ }^{4}$, to promote accessible health information and elevate the visibility of deaf women in STEM. Panko began by engaging focus groups of her desired audience, deaf $5^{\text {th }}$ grade girls, using their feedback to inform the book currently in production.

Paula Garcia Todd, along with Science $\mathrm{ATL}^{5}$, set up partnerships between teachers and STEM professionals in the Atlanta region. Todd reported that because of the partnerships and the activities they spawned, "schools got new gardens, some classrooms got creative with "brown bag" STEM kits that were picked up at the school for activities to be done at home, we had winners in the local Rube Goldberg competition, and an underwater robotics team that won their regional competition and advanced to nationals thanks to help from their STEM professional" (Todd, 2021).

In a 2020 survey, ambassadors said they found the program valuable, reportedly doing more public engagement thanks to the

${ }^{3}$ http://www.ifthenshecan.org

${ }^{4}$ https://www.tiffanypankomdmba.com/abc-book

${ }^{5} \mathrm{https}: / /$ scienceatl.org support, and had positive attitudes about their abilities to engage. Evaluation of the IF/THEN" ${ }^{\circledR}$ "She Can Change the World Projects" projects is currently underway.

\section{Leshner Leadership Institute}

The AAAS Alan I. Leshner Leadership Institute for Public Engagement with Science ${ }^{6}$, launched in 2015 , provides both training and resources for enabling public engagement, including seed funding, staff support, and peer networking, to cohorts of 10-15 scientists working within a related subject area (e.g., climate change, infectious disease). These scientists commit to a year of intensive public engagement and advocating for support within their institutions, as one of the goals of the program is to shift institutional culture and capacity through empowering these leaders.

AAAS Leshner fellows have reported that AAAS' credibility helps them drive institutional support for public engagement within their professional communities, including through seeking out engagement-related leadership positions, establishing awards (such Wendy Jepson's work on the Public Engagement Award for faculty at the Texas A\&M University College of Geosciences), cowriting articles in society journals (Jefferson et al., 2018; Kenney et al., 2020), and organizing engagement-related sessions at society meetings, in one case resulting in an engagementfocused section in Freshwater Science (Hopfensperger et al., 2021). At the University of Minnesota's Institute on the Environment (IonE), three Leshner fellows, including Institute director Jessica Hellmann, infused a greater public engagement focus and incorporated AAAS material into the IonE Associates program $^{7}$ which supports early-career faculty doing publicoriented research.

Fellow Kate Brauman illustrates the effectiveness of bridging training and resources to enable long-term, influential sciencesociety interactions. In 2019, Brauman was invited to participate in a Congressional hearing on biodiversity losses based on her work as a coordinating lead author on the Global Assessment of the Inter-Governmental Platform on Biodiversity and Ecosystem Services. ${ }^{8}$ At her request, Center and AAAS government relations staff provided coaching that helped her prepare for providing testimony and answering lawmakers' questions. Brauman later became a AAAS Science and Technology Policy Fellow ${ }^{9}$ placed at the U.S. Department of Defense where she helped to develop a methodology for assessing water security risk at military installations.

AAAS conducted an external evaluation of the program in 2021 with a 70 percent response rate from the five cohorts of fellows. The results were encouraging, with 72 percent of respondents saying the fellowship contributed to their career advancement, 78 percent of respondents saying they are now regularly advocating for placing a higher value on public engagement with their leadership, 65 percent saying they had

${ }^{6}$ https://www.aaas.org/ll

${ }^{7}$ http://environment.umn.edu/fellows-grants/ione-associates

${ }^{8}$ https://www.congress.gov/event/116th-congress/house-event/109573

${ }^{9}$ https://www.aaas.org/programs/science-technology-policy-fellowships 
started or increased expectations for students, advisees, or junior staff to participate in public engagement, and 48 percent saying their engagement is influencing audiences' lives, work, or decision-making. Findings from this evaluation (publication forthcoming) will inform ideas for future cohorts including improved training, stronger peer networking, and guidance for pursuing collaborative public engagement, such as community partnerships.

New to this program, AAAS is holding focus groups to gather input on the framing, focus, and goals for the next cohort of fellows, and future resources will also incorporate existing inclusive public engagement guidance from sources such as the Equity Compass (YESTEM Project UK Team, 2020), the 2020 Inclusive SciComm Report (Canfield and Menezes, 2020), and the CAISE Broadening Perspectives Toolkit (Center for Advancement of Informal Science Education, 2021).

\section{PUBLIC ENGAGEMENT IN PRACTICE}

A third pillar of support is facilitating opportunities to practice engagement and highlighting examples of replicable engagement. Institutions can provide logistical support and connections to underserved audiences for individuals, who should not bear the sole responsibility of creating and maintaining engagement efforts. We reflect on two projects as examples for scientists and institutions.

\section{Family Science Days}

The Center launched the AAAS Family Science Days ${ }^{10}$ program in 2004 as a free public science festival with hands-on activities for children and their families. Held alongside the AAAS Annual Meeting, which takes place in a different city each year, the program sought to increase engagement between meeting attendees and the local public.

An essential element of the program is demonstrating the concept of public engagement and its value to Annual Meeting participants, again with an aim of creating overall culture change. Booth exhibitors include local science groups, such as the neuroscience and genome sciences departments at the University of Washington for the 2020 event in Seattle, and repeat exhibitors, including Science Storytellers ${ }^{11}$ and Math Matters to Me. ${ }^{12}$ The "Meet a Scientist" stage show features scientists, including meeting participants, who give interactive performances incorporating visuals or props.

In recent years, the Center committed to assembling a more diverse lineup of scientists for the stage show by featuring both a range of scientific disciplines and scientists with a broad spectrum of identities and lived experiences, ensuring a wider range of children could see themselves represented. This was a change from a tradition of featuring well-known scientists, often from similar backgrounds. When able, Center staff also worked with local organizations or schools to provide transportation and lunch to children who otherwise would not have been able to attend, actively pursuing a representative audience to increase access to science. The Center also committed to being inclusive, providing accommodations including a sensory friendly hour. ${ }^{13}$

Attendees have indicated in post-event surveys that the event had an impact, sharing reflections such as, "My daughter... put up a "lab" in her room and is recording her experiments in the notebook she got at the event. Great inspiration to make science fun!" In a 2020 survey, three-quarters of exhibitors and stage show speakers agreed that "this public engagement activity provided me with an opportunity to learn from the broader community" and four out of five agreed they "felt enlightened by ideas shared by participants at this public engagement event."

\section{How We Respond}

In addition to opportunities to practice engagement or see it in action, scientists need to see varied examples of effective, two-way engagement. The Center launched the How We Respond ${ }^{14}$ climate communication project in 2019 to demonstrate the many ways scientists can collaborate with communities to respond to climate change. The project highlights community-level responses via 24 multimedia stories and a plain-language report about climate change responses and includes Spanish translations.

The Center sought to be inclusive by convening representative advisory committees and focus groups to shape the project. The project also featured a diversity of responses and communities, considering geography, population density, demographics, and ways of knowing. Based on participant feedback on the first round of stories in 2019, the Center actively recruited more communities of color to feature in 2021, aiming to support and highlight them and not appropriate their stories and images. A 2019 accessibility audit also informed modifications to the project's website, including increasing color contrast for better readability and incorporating alt text.

\section{REWARDS}

Institutions who highlight successful, replicable engagement show they prioritize it and provide a bridge from training to application. A final pillar for demonstrating the value of public engagement is offering incentives. Awards and incentives recognize scientists for excellent public engagement, encouraging others to pursue similar paths and elevating the profiles of scientists who engage. AAAS's public engagement awards provide an example of ways to meaningfully reward scientists whose efforts might otherwise go unrecognized.

\footnotetext{
${ }^{13}$ A sensory friendly hour provides attendees with clear expectations for what they might experience, such as light and sound stimuli, giving them more agency to choose how to interact with an event.

${ }^{14} \mathrm{https}$ ///howwerespond.aaas.org
} 


\section{Public Engagement Awards}

AAAS offers two awards recognizing scientists for significant contributions to public engagement ${ }^{15}$, the AAAS Mani L. Bhaumik Award for Public Engagement with Science, established in 1987, and the AAAS Early Career Award for Public Engagement with Science, established in 2010. Recipients of each award receive a monetary prize, a commemorative plaque, and recognition at the AAAS Annual Meeting. In providing monetary awards, AAAS reinforces that public engagement is important, encouraging other institutions to prioritize it in professional portfolios. We also publicly recognize finalists for the Early Career Award, to amplify additional excellent public engagement and because recognition is particularly impactful for early-career scientists who might be discouraged from pursuing activities deemed outside of professional responsibilities.

Awards also highlight scientists modeling replicable engagement strategies. Fairfield University professor and former college basketball player John Drazan, the 2020 AAAS Early Career Award recipient, engages sports enthusiasts. Early in Covid-19 pandemic, Drazen connected infectious disease experts with sports podcast hosts, bringing scientific expertise to a community grappling with impacts such as the 2020 NBA season's cancellation (Brockmeier, 2020). University of Illinois Urbana-Champaign Assistant Professor Esther Ngumbi, the 2021 AAAS Mani L. Bhaumik Award recipient, works with farmers, using insights from her research on insects, plants, and soil microbes to introduce them to new techniques, for example, and engages university students in Kenya in projects to reduce rural hunger there (Cohen, 2021).

Recently, the Center prioritized making the awards nomination process more equitable and engagement-focused. Previously, letters of support-often written by high-profile academics prioritizing academic prestige-were the primary nomination vehicle. Now, the Center requests statements addressing nominees' efforts to prioritize dialogue and curriculum vitae highlighting public engagement work. The result has been more representative nomination pools, increases in self-nominations from researchers in unsupportive academic environments, and letters from community members who say more about nominees' impacts. To build on this, we are collecting demographic information, providing reviewers with anti-bias training, considering review committee composition,

\section{REFERENCES}

AAAS Center for Public Engagement with Science and Technology (2016). Theory of Change for Public Engagement with Science. Available at: https:/www.aaas.org/ programs/center-public-engagement-science-and-technology/theory-change-publicengagement-science (Accessed September 20, 2021).

Aurbach, E. L., Prater, K. E., Cloyd, E. T., and Lindenfeld, L. (2019). Foundational Skills for Science Communication: A Preliminary Framework. White Paper. The University of Michigan. Available at: http://hdl.handle.net/2027.42/150489 (Accessed September 20, 2021). doi:10.3998/2027.42/150489 and ensuring evaluation metrics aren't inadvertently exclusionary.

\section{CONCLUSION}

Through training, resources, practice, and rewards, the AAAS Center for Public Engagement with Science and Technology builds capacity for scientists to engage the public on societal issues and signals that public engagement should be valued, supported, and celebrated. Even for larger organizations like AAAS, there are barriers to implementing and sustaining public engagement programs including funding and staffing constraints, limiting our ability to more adequately and equitably serve scientists. For example, we recognize that registration fees for Communicating Science workshops are a barrier to entry, we see a need for more sustained alumni networks with staff support, and we acknowledge that greater fellowship and ambassadorship project seed funding might allow them to do more. Despite these and other areas for improvement, we encourage other institutions to consider these approaches and we welcome conversations about inclusive public engagement support mechanisms that serve the public and strengthen the scientific enterprise.

\section{DATA AVAILABILITY STATEMENT}

The original contributions presented in the study are included in the article/supplementary material, further inquiries can be directed to the corresponding author.

\section{AUTHOR CONTRIBUTIONS}

All authors listed have made a substantial, direct, and intellectual contribution to the work and approved it for publication.

\section{ACKNOWLEDGMENTS}

The authors gratefully acknowledge Stacey Baker, Emily Therese Cloyd, Elizabeth Crocker, and Kristin Lewis for providing feedback for this paper.

Bartel, B., Agopian, M., and Bohon, W. (2019). The Unexpected Benefits of Science Communication Training. EOS 100. doi:10.1029/2019eo129023

Braha, J. (2015). Public Engagement with Science and Informal Science Education. Informal. Learn. Rev. 2015, 18-23.

Brockmeier, E. K. (2020). Sports, STEM, and Science Communication. Penn Today. Available at: https://penntoday.upenn.edu/news/sports-stem-andscience-communication (Accessed September 20, 2021).

Canfield, K., and Menezes, S. (2020). The State of Inclusive Science Communication: A Landscape Study. Kingston: Metcalf Institute, University of Rhode Island, 77, 1-2. Available at: https://inclusivescicomm.org/files/State-of-Inclusive-SciComm-2020.pdf. Center for Advancement of Informal Science Education (2021). Broadening Perspectives on Broadening Participation in STEM Toolkit. Available at: https://www.informalscience.org/broadening-perspectives (Accessed September 20, 2021).

\footnotetext{
${ }^{15} \mathrm{https} / / /$ www.aaas.org/page/awards
} 
Cohen, A. D. (2021). Entomologist Esther Ngumbi Receives 2021 AAAS Mani L. Bhaumik Award for Public Engagement with Science. AAAS News. Available at: https://www.aaas.org/news/entomologist-esther-ngumbi-receives-2021-aaas-mani1-bhaumik-award-public-engagement-science (Accessed September 20, 2021).

Cooke, M., Child, C. R., Sibert, E. C., von Hagke, C., and Zihms, S. G. (2020). Caption This! Best Practices for Live Captioning Presentations. EOS 101, 221-227. doi:10.1029/2020eo150246

Crameri, F., Shephard, G. E., and Heron, P. J. (2020). The Misuse of Colour in Science Communication. Nat. Commun. 11, 5444. doi:10.1038/s41467-02019160-7

Geena Davis Institute on Gender in Media (2018). Portray Her: Representations of Women in STEM Characters in Media. Available at: https://seejane.org/wpcontent/uploads/portray-her-full-report.pdf (Accessed September 20, 2021).

Hopfensperger, K. N., Larson, E. I., Washko, S. E., and Moody, E. K. (2021). Elevate Your Work through Incorporation of Public Engagement. Freshw. Sci. 40. doi:10.1086/712607

Jefferson, A. J., Kenney, M. A., Hill, T. M., and Selin, N. E. (2018). Universities Can lead the Way Supporting Engaged Geoscientists. EOS 99. doi:10.1029/ 2018 eo111567

Kenney, M. A., Davis, F., Sutton-Grier, A. E., Anderson, S., Therese Cloyd, E., Garramon Merkle, B., et al. (2020). Increasing the Impact of Public Engagement within and beyond the Ecological Society of America. Bull. Ecol. Soc. Am. 101 (4), e01773. doi:10.1002/bes2.1773

Leshner, A. I. (2003). Public Engagement with Science. Science 299 (5609), 977. doi:10.1126/science.299.5609.977

MacArthur, B. L., Lindenfeld, L. A., Aurbach, E., Bevan, B., and Newman, T. P. (2020). Bridging Science with Society: Defining Pathways for Engagement. Commun. Cent. J. 6, 62-78. Available at: http://libjournal.uncg.edu/ccj/article/ view/2062.

Murchie, K. J., and Diomede, D. (2020). Fundamentals of Graphic Design-Essential Tools for Effective Visual Science Communication. Facets 5, 409-422. doi:10.1139/facets-2018-0049
Risien, J., and Storksdieck, M. (2018). Unveiling Impact Identities: A Path for Connecting Science and Society. Integr. Comp. Biol. 58 (1), 58-66. doi:10.1093/ icb/icy011

Storksdieck, M., Stylinski, C., and Bailey, D. (2016). Typology for Public Engagement with Science: A Conceptual Framework for Public Engagement Involving Scientists. Corvallis, OR: Center for Research on Lifelong STEM Learning.

Todd, P. G. (2021). Creating Successful Partnerships between Schools and STEM Professionals. Public Engagement Reflections. Available at: https://www.aaas.org/ programs/center-public-engagement-science-and-technology/reflections/creatingsuccessful (Accessed September 20, 2021).

YESTEM Project UK Team (2020). The Equity Compass: A Tool for Supporting Socially Just Practice. Available at: https://yestem.org/wp-content/uploads/ 2020/10/EQUITY-COMPASS-YESTEM-INSIGHT.pdf (Accessed September 20, 2021).

Conflict of Interest: The authors declare that the research was conducted in the absence of any commercial or financial relationships that could be construed as a potential conflict of interest.

Publisher's Note: All claims expressed in this article are solely those of the authors and do not necessarily represent those of their affiliated organizations, or those of the publisher, the editors and the reviewers. Any product that may be evaluated in this article, or claim that may be made by its manufacturer, is not guaranteed or endorsed by the publisher.

Copyright (C) 2022 Kimbrell, Philippe and Longshore. This is an open-access article distributed under the terms of the Creative Commons Attribution License (CC BY). The use, distribution or reproduction in other forums is permitted, provided the original author(s) and the copyright owner(s) are credited and that the original publication in this journal is cited, in accordance with accepted academic practice. No use, distribution or reproduction is permitted which does not comply with these terms. 